Cite this: Phys. Chem. Chem. Phys., 2011, 13, 2335-2341

\title{
Trimethylglycine complexes with carboxylic acids and HF: solvation by a polar aprotic solvent $\dagger$
}

\author{
Jing Guo, ${ }^{a}$ Benjamin Koeppe $^{a}$ and Peter M. Tolstoy ${ }^{* a b}$ \\ Received 31st August 2010, Accepted 29th October 2010 \\ DOI: $10.1039 / \mathrm{c0cp01659d}$
}

A series of strong $\mathrm{H}$-bonded complexes of trimethylglycine, also known as betaine, with acetic, chloroacetic, dichloroacetic, trifluoroacetic and hydrofluoric acids as well as the homo-conjugated cation of betaine with trifluoroacetate as the counteranion were investigated by low-temperature (120-160 K) liquid-state NMR spectroscopy using $\mathrm{CDF}_{3} / \mathrm{CDF}_{2} \mathrm{Cl}$ mixture as the solvent. The temperature dependencies of ${ }^{1} \mathrm{H}$ NMR chemical shifts are analyzed in terms of the solvent-solute interactions. The experimental data are explained assuming the combined action of two main effects. Firstly, the solvent ordering around the negatively charged OHX region of the complex $(\mathrm{X}=\mathrm{O}, \mathrm{F})$ at low temperatures, which leads to a contraction and symmetrisation of the H-bond; this effect dominates for the homo-conjugated cation of betaine. Secondly, at low temperatures structures with a larger dipole moment are preferentially stabilized, an effect which dominates for the neutral betaine-acid complexes. The way this second contribution affects the H-bond geometry seems to depend on the proton position. For the $\mathrm{Be}^{+} \mathrm{COO}^{-} \cdots \mathrm{HOOCCH}_{3}$ complex $\left(\mathrm{Be}=\left(\mathrm{CH}_{3}\right)_{3} \mathrm{NCH}_{2}-\right)$ the proton displaces towards the hydrogen bond center (H-bond symmetrisation, $\mathrm{O} \cdots \mathrm{O}$ contraction). In contrast, for the $\mathrm{Be}^{+} \mathrm{COOH} \ldots{ }^{-} \mathrm{OOCCF}_{3}$ complex the proton shifts further away from the center, closer to the betaine moiety (H-bond asymmetrisation, $\mathrm{O} \cdots \mathrm{O}$ elongation). Hydrogen bond geometries and their changes upon lowering the temperature were estimated using previously published H-bond correlations.

\section{Introduction}

Geometries of intermolecular hydrogen bonds in solutions are often an elusive subject, to a large extent owing to their fluxional nature. For a given pair of partners a small change in the local environment might induce a large change in the hydrogen bond geometry. The high nuclear polarizability of the bridging proton makes it especially susceptible to the local electric field. The latter can be created by the polar molecules or groups in the proximity of the complex or by the external electric fields. ${ }^{1,2}$ For hydrogen bonded complexes in the liquid state and in solution main electrostatic interactions come from the first solvation shell, which might include the counterion for a charged system. ${ }^{1,3,4}$ Information about the structure of the solvation shell is usually rather scarce, especially when it comes to the position of the counterion. ${ }^{5}$ In theoretical calculations the solvent effects can be modeled by a number of approaches, ranging from implicit polarized continuum models ${ }^{6,7}$ to explicit $\mathrm{QM} / \mathrm{MM}$ or ab initio treatments of the solvent molecules. ${ }^{8-10}$ In the experiment, the solvent structure can be studied by a large

${ }^{a}$ Institute of Chemistry and Biochemistry, Free University of Berlin, Germany.E-mail: tolstoy@chemie.fu-berlin.de

${ }^{b}$ V.A. Fock Institute of Physics, St. Petersburg State University, Russia $\dagger$ Electronic supplementary information (ESI) available: Additional ${ }^{1}$ H NMR spectra used for the signal assignment, line width of the solvent peak for some complexes and the complete set of estimated $r(\mathrm{OH})$ and $r(\mathrm{HO})$ distances. See DOI: $10.1039 / \mathrm{c} 0 \mathrm{cp} 01659 \mathrm{~d}$ variety of methods, as it affects most of the physical and chemical properties of the solute. For example, neutron diffraction can give an atom-to-atom radial distribution function. ${ }^{11}$ Among many spectroscopic techniques, fluorescence labeling, ${ }^{12}$ terahertz, ${ }^{13}$ pump-probe $\mathrm{IR}^{14}$ and $\mathrm{NMR}^{15}$ spectroscopies were used to study the structure of solvation shells. In our recent publication we have employed NMR spectroscopy to study the effects of the counterion and the solvent polarity on the cationic NHN hydrogen bonds in a series of protonated proton sponges dissolved in polar aprotic media. ${ }^{3}$ It was shown that the larger is the counteranion, the more symmetrically it is placed near the cationic H-bond. Besides, lowering the temperature led to a symmetrisation of the NHN hydrogen bonds because of the combination of two effects: (i) better separation of the H-bond and its counterion and (ii) the solvent ordering around the $(\mathrm{NHN})^{+}$fragment. Similar effects have been previously observed for the $(\mathrm{OHO})^{-}$hydrogen bonds in the homoconjugated anions of acetic acid, however the solvent ordering was not explicitly invoked. ${ }^{16}$ Though the separation of the resulting temperature dependence into two parts is to a certain degree artificial, it would be interesting to try to isolate the effects of the counterion from the effects of the solvent ordering. For that it would be advantageous to have a direct control over the position of the counterion. A promising way might be to fix the counterion intramolecularly. Recently, Perrin and Lau have used this stratagem to study strong intramolecular $\mathrm{OHO}$ 

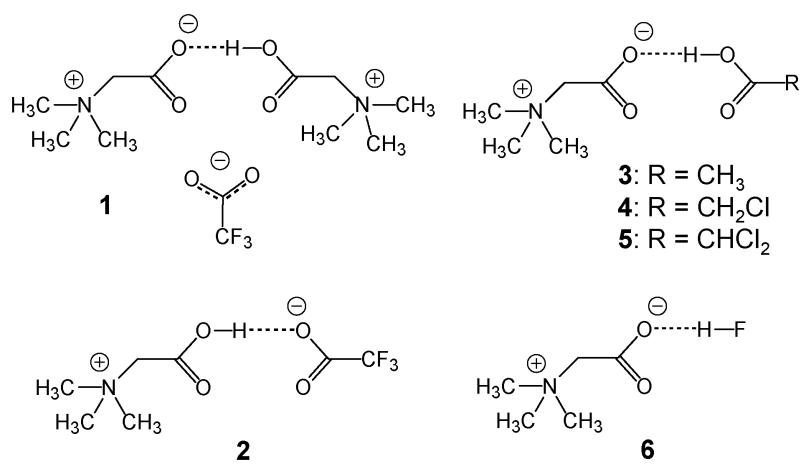

Fig. 1 Schematic structure of the complexes studied in this work. Positions of the protons in the H-bonds are estimated experimentally as described in the text.

hydrogen bonds in zwitterionic phthalate anions. ${ }^{17}$ In these compounds the positively charged nitrogen atom, which compensates the charge of the anionic hydrogen bridge, does not perturb its symmetry as it is placed symmetrically with respect to the $\mathrm{OHO}$ fragment. Another source of complexes with a fixed position of the counterion could be the intermolecular complexes with betaines as proton acceptors. Betaines are a widely studied class of zwitterionic compounds derived from amino acids, comprised of a carboxylate anion covalently linked to an ammonium cation. A number of crystalline complexes of betaines with inorganic acids, ${ }^{18,19}$ carboxylic acids ${ }^{20-24}$ and phenols, ${ }^{25}$ as well as homo-conjugated cations of betaines ${ }^{19,26,27}$ have been identified previously by NMR, UV-Vis, IR spectroscopy and X-ray diffraction. Unfortunately, there are very few experimental data concerning the effects of the aprotic solvent on the H-bond geometry of betaine complexes. ${ }^{20,22,28}$

Here we present a ${ }^{1} \mathrm{H}$ NMR study of the intermolecular complexes of trimethylglycine (for shortness, referred to as betaine in this paper) with acetic (3), chloroacetic (4), dichloroacetic (5), trifluoroacetic (2) and hydrofluoric (6) acids as well as the homo-conjugated cation of betaine (1) with trifluoroacetate as the counterion dissolved in the freonic mixture $\left(\mathrm{CDF}_{3} / \mathrm{CDF}_{2} \mathrm{Cl}\right)$. Structures of the abovementioned complexes are schematically shown in Fig. 1. We have chosen to draw the all cis forms of complexes, as these are the most stable conformers in the gas phase (according to our DFT calculations; see also the Discussion section). However, there is no direct experimental evidence, which would allow us to rule out trans conformers.

The goal of the work was to follow with NMR spectroscopy the effects of the solvent ordering at low temperatures on the hydrogen bond geometry. The presented complexes are advantageous for this task, because in the case of $\mathbf{1}$ the trifluoroacetate counterion is expected to be far away from the negatively charged $(\mathrm{OHO})^{-}$bridge, and in the case of 2-6 the positively charged counterion is fixed in space with respect to the anionic hydrogen bridge, thus does not obscure the observation of the solvent ordering effects.

\section{Experimental}

\section{Chemicals}

Trimethylglycine, trifluoroacetic acid and hydrofluoric acid were purchased from Aldrich and used without further purification.

\section{Betaine complexes with trifluoroacetic acid}

$3 \mathrm{mg}$ of trimethylglycine were dissolved in $3 \mathrm{ml}$ of methanol and 0.5 equiv. of trifluoroacetic acid was added dropwise. After that $30 \mu \mathrm{l}$ of reaction mixture was transferred into the NMR sample tube and the solvent was evaporated overnight under vacuum.

Betaine complexes with acetic, chloroacetic and dichloroacetic acids

$3 \mathrm{mg}$ of trimethylglycine were weighed and dissolved in $3 \mathrm{ml}$ of methanol. $30 \mu \mathrm{l}$ of solution was transferred into the NMR sample tube and the solvent was evaporated. Then the corresponding acid dissolved in $\mathrm{CD}_{2} \mathrm{Cl}_{2}$ was added directly to the sample tube in equimolar amount. The volume of the added solution was $c a .3 \mu \mathrm{l}$.

\section{Betaine complex with hydrofluoric acid}

A stoichiometric amount of hydrofluoric acid $\left(35 \mathrm{wt} \%\right.$ in $\left.\mathrm{H}_{2} \mathrm{O}\right)$ was added to a methanol solution of trimethylglycine in a polyethylene flask. Methanol and water were removed on a rotary evaporator. After that $\mathrm{CH}_{2} \mathrm{Cl}_{2}$ was repeatedly added and pumped away for drying purpose. The resulting solid substance was dissolved in $\mathrm{CD}_{2} \mathrm{Cl}_{2}$ and transferred into an NMR tube.

\section{NMR sample preparation}

Thick-walled sample NMR tubes equipped with PTFE valves (Wilmad, Buena) were used. The solvent, $\mathrm{CDF}_{3} / \mathrm{CDF}_{2} \mathrm{Cl}$ (freezing point below $100 \mathrm{~K}$ ), prepared by the modified method described in ref. 29 was added to the samples by vacuum transfer. The overall concentration of the complex in the sample, estimated by measuring the volume of the solution at low temperatures (around $120 \mathrm{~K}$ ), was about $0.001 \mathrm{M}$.

\section{NMR measurements}

The Bruker AMX-500 NMR spectrometer used was equipped with a low-temperature probe which allowed us to perform experiments down to $100 \mathrm{~K} .{ }^{1} \mathrm{H}$ NMR spectra were measured every $10 \mathrm{~K}$ in the temperature range from $160 \mathrm{~K}$ to $120 \mathrm{~K}$. Chemical shifts were measured using fluoroform, $\mathrm{CHF}_{2} \mathrm{Cl}$, as internal standard, and converted to the conventional TMS scale.

\section{Signal assignment}

To assign the NMR signals we have performed a series of additional experiments on tetraethylammonium (TEA) hydrogen bis-acetate, TEA hydrogen chloroacetate, TEA hydrogen dichloroacetate and TEA hydrogen trifluoroacetate (see Fig. S1 in ESI $\dagger$ ). Homo-conjugates of acetic, chloroacetic and trifluoroacetic acids display ${ }^{1} \mathrm{H}$ NMR signals at chemical shifts different from those reported in this paper for corresponding betaine complexes (namely, 2, 3 and 4), which supports our assignment. In contrast, the ${ }^{1} \mathrm{H}$ chemical shifts of the bridging protons in betaine homo-conjugate $\mathbf{1}$ and complex 5 are quite similar (around $19.7 \mathrm{ppm}$ ). Thus, in order to make the correct assignment we have compared the integrated intensities of the bridging proton signal with that of the $-\mathrm{CHCl}_{2}$ group of the acid, as well as $\mathrm{CH}_{2}$ and $\mathrm{CH}_{3}$ groups of the betaine (see Fig. S2 in ESI $\dagger$ ). Apparently, the hydrogenbonded complex which stays in solution at low temperatures contains betaine and dichloroacetate moieties in $1: 1$ ratio. 
A similar check of integrated intensities was used to establish the stoichiometry of complexes $\mathbf{3}$ and $\mathbf{4}$.

\section{Results}

\section{NMR spectra}

In Fig. 2 the low-field parts of ${ }^{1} \mathrm{H}$ NMR spectra of the sample containing trifluoroacetic acid and the double access of betaine are presented. The low-field signal is assigned to the homoconjugated cation of betaine with trifluoroacetate as the counteranion (1, see Fig. 1). Note that if the counteranion was not trifluoroacetate but the homo-conjugated anion of trifluoroacetic acid, it would lead to an extra proton signal.

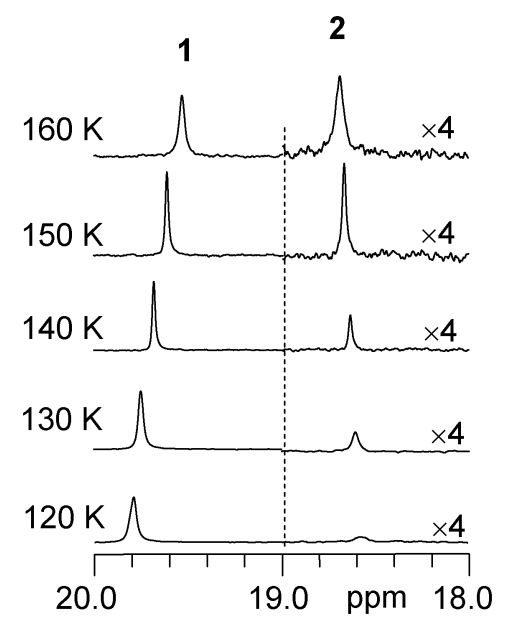

Fig. 2 Low-field parts of ${ }^{1} \mathrm{H}$ spectra of the sample containing betaine and $\mathrm{CF}_{3} \mathrm{COOH}$ dissolved in $\mathrm{CDF}_{3} / \mathrm{CDF}_{2} \mathrm{Cl}$. The NMR parameters are collected in Table 1.

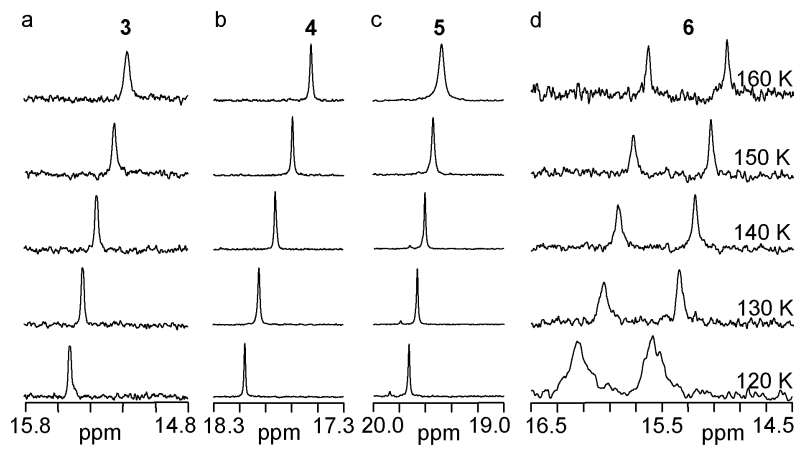

Fig. 3 Low-field parts of ${ }^{1} \mathrm{H}$ spectra of the samples containing $0.001 \mathrm{M}$ of complexes (a) 3, (b) $\mathbf{4}$, (c) 5 and (d) 6 dissolved in $\mathrm{CDF}_{3} / \mathrm{CDF}_{2} \mathrm{Cl}$. The NMR parameters are collected in Table 1.
Indeed, additional experiments show that the proton chemical shift of the tetraethylammonium hydrogen bis-trifluoroacetate dissolved in $\mathrm{CDF}_{3} / \mathrm{CDF}_{2} \mathrm{Cl}$ is $20.07 \mathrm{ppm}$ at $120 \mathrm{~K}$ (see Fig. S1 in $\mathrm{ESI} \dagger$ ). The signal at around $18.5 \mathrm{ppm}$ in Fig. 2 is assigned to the betaine-trifluoroacetic acid complex 2 . The signal intensities of $\mathbf{1}$ and $\mathbf{2}$ drop at lower temperatures due to the decrease of solubility. The chemical shifts of both signals show temperature dependence but with different trends. Upon lowering the temperature from $160 \mathrm{~K}$ to $120 \mathrm{~K}$, the bridging proton signal of 1 shifts to the lower field from $\sim 19.5 \mathrm{ppm}$ to $\sim 19.8 \mathrm{ppm}$ while the signal of 2 shifts from $18.7 \mathrm{ppm}$ to the higher field by about $0.1 \mathrm{ppm}$.

In Fig. 3 temperature dependent ${ }^{1} \mathrm{H}$ spectra of complexes 3-6 are shown. Signals of all four complexes shift to the lower field as the temperature decreases. Signals of complex 6 are split into doublets due to the ${ }^{1} J(\mathrm{HF})$ spin-spin coupling, which is close to $300 \mathrm{~Hz}$ at all measured temperatures. The solubility of complex $\mathbf{6}$ in Freon drops dramatically at low temperatures. The precipitate deposits on the sample walls, which affects the homogeneity of the magnetic field and leads to signal broadening. The solubility drop was not that large for other complexes, where we were able to maintain relatively good field homogeneity even at the lowest temperature (also for other complexes the precipitate was predominantly formed at the bottom of the sample tube). To illustrate this point we show the temperature-dependent widths of the solvent signals for samples containing complexes $\mathbf{5}$ and $\mathbf{6}$ in ESI. $\dagger$ The temperature dependence of the ${ }^{1} \mathrm{H}$ chemical shifts of complexes 1-6 and coupling constants of $\mathbf{6}$ are collected in Table 1.

\section{Discussion}

This section is structured as follows. Firstly, we will qualitatively discuss the ${ }^{1} \mathrm{H}$ NMR chemical shifts of complexes 1-6 in order to establish their protonation states. Then we will discuss the geometric effects which the solvation shell might have on the proton donor-acceptor interaction. Secondly, we will convert the experimentally observed temperature-dependent chemical shifts into the interatomic distances using the previously established hydrogen bond correlations. The latter will allow us to estimate the effects of the solvent ordering on the distances from the bridging proton to the heavy atoms.

\section{Solvation of the betaine complexes by a polar solvent}

Homo-conjugate of betaine 1. The positive charge of $\mathbf{1}$ is compensated by the $\mathrm{CF}_{3} \mathrm{COO}^{-}$anion. The latter forms a contact ion pair or a solvent-separated ion pair with the homo-conjugate and is likely to be placed close to the

Table 1 Experimental ${ }^{1} \mathrm{H}$ NMR chemical shifts of the bridging proton for complexes 1-6 as well as the ${ }^{1} J(\mathrm{HF})$ coupling for complex $\mathbf{6}$

\begin{tabular}{|c|c|c|c|c|c|c|c|}
\hline \multirow[b]{2}{*}{$T / \mathrm{K}$} & \multirow{2}{*}{$\frac{\mathbf{1}}{\delta\left({ }^{1} \mathrm{H}\right) / \mathrm{ppm}}$} & \multirow{2}{*}{$\frac{2}{\delta\left({ }^{1} \mathrm{H}\right) / \mathrm{ppm}}$} & \multirow{2}{*}{$\frac{3}{\delta\left({ }^{1} \mathrm{H}\right) / \mathrm{ppm}}$} & \multirow{2}{*}{$\frac{4}{\delta\left({ }^{1} \mathrm{H}\right) / \mathrm{ppm}}$} & \multirow{2}{*}{$\frac{5}{\delta\left({ }^{1} \mathrm{H}\right) / \mathrm{ppm}}$} & \multicolumn{2}{|l|}{6} \\
\hline & & & & & & $\delta\left({ }^{1} \mathrm{H}\right) / \mathrm{ppm}$ & ${ }^{1} J(\mathrm{HF}) / \mathrm{Hz}$ \\
\hline 160 & 19.532 & 18.691 & 15.171 & 17.552 & 19.476 & 15.305 & 300.57 \\
\hline 150 & 19.612 & 18.669 & 15.254 & 17.693 & 19.540 & 15.425 & 295.89 \\
\hline 140 & 19.683 & 18.636 & 15.357 & 17.824 & 19.609 & 15.542 & 292.04 \\
\hline 130 & 19.748 & 18.605 & 15.442 & 17.947 & 19.666 & 15.658 & 289.62 \\
\hline 120 & 19.808 & 18.592 & 15.520 & 18.061 & 19.731 & 15.853 & 286.77 \\
\hline
\end{tabular}


positively charged $\left(\mathrm{CH}_{3}\right)_{3} \mathrm{~N}^{+} \mathrm{CH}_{2}$ - fragments, away from the negatively charged $\mathrm{OHO}$ bridge. Thus, in the first approximation the H-bond is not perturbed by the counteranion. The proton chemical shift around $20 \mathrm{ppm}$ indicates a short $\mathrm{O} \cdots \mathrm{O}$ distance, though it is hard to tell whether the proton is located in the H-bond center or it is involved in a fast exchange between $\mathrm{O} \cdots \mathrm{H} \cdots{ }^{-} \mathrm{O}$ and $\mathrm{O}^{-} \cdots \mathrm{H} \cdots \mathrm{O}$ forms. In fact, it is reasonable to expect that the homo-conjugate $\mathbf{1}$ is present in the solution as a distribution of "solvatomers" 17 which differ in the structure of the solvation shell and thus in the H-bond geometry. In the ensemble there might be structures with a central proton position, but the most probable ones are perhaps somewhat asymmetric. ${ }^{8}$ The short $\mathrm{O} \cdots \mathrm{O}$ distance is a common feature of many betaine homo-conjugates with various counterions in the solid state, the typical values being $r(\mathrm{OO})=2.44-2.57 \AA{ }^{19}$

The low-field shift of the proton signals at the low temperature can be explained in terms of the solvent-solute interactions. In the solution complex $\mathbf{1}$ is surrounded by polar $\mathrm{CDF}_{3}$ and $\mathrm{CDF}_{2} \mathrm{Cl}$ molecules. The lower the temperature, the more ordered the solvent molecules are around the hydrogen bridge (i.e. the equilibrium shifts towards the more structured solvatomers). Ordering of the solvent manifests itself also in the raise of the dielectric constant of the bulk solvent (for the $\mathrm{CHF}_{3}: \mathrm{CHF}_{2} \mathrm{Cl} 1: 1$ mixture $\varepsilon$ rises from $c a .20$ at $170 \mathrm{~K}$ to ca. 40 at $100 \mathrm{~K}^{30}$ ). In the case of complex 1 lowering the temperature leads to an increase of the ${ }^{1} \mathrm{H}$ NMR chemical shift, which indicates structures with a more central average proton position and shorter $\mathrm{O} \cdots \mathrm{O}$ distances. ${ }^{31}$ We believe that the reason for these changes is the preferential stabilization of the structures with the more localized negative charge, achieved at shorter $\mathrm{O} \cdots \mathrm{O}$ distances. This scenario is schematically shown in Fig. 4a. A similar temperature dependence of the ${ }^{1} \mathrm{H}$ NMR chemical shift has been previously observed for the homo-conjugate of acetic acid with tetrabutylammonium as the counter-cation. ${ }^{16}$ This
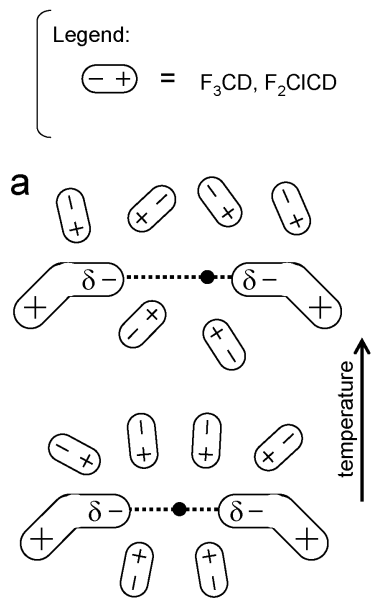

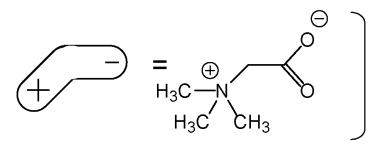

b

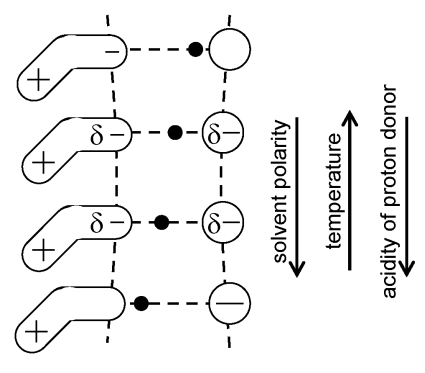

Fig. 4 (a) Schematic representation of the solvation of the homoconjugated cation of betaine by the polar aprotic molecules at higher (above) and lower (below) temperatures; (b) schematic representation of the full proton transfer pathway from the proton donor to the betaine. While it takes a series of proton donors to cover the full pathway, parts of it could be covered by changing the temperature or the solvent polarity for a given complex. See text for more details. similarity suggests that in both cases the influence of the counterion on the solvation of the $(\mathrm{OHO})^{-}$fragment is small.

Betaine trifluoroacetic acid 2. The $1: 1$ complex 2 exists in solution only as a minor species in the equilibrium with the homo-conjugate 1 (see Fig. 2, right). Apparently, due to its high proton donating ability the trifluoroacetic acid prefers to give the proton away and to become a counteranion to a homo-conjugated betaine cation. We note that the formation of homo-conjugated cations can help to explain the UV-Vis spectra of pyridine-betaine mixture with 2,6-dichloro-4nitrophenol in $\mathrm{CH}_{2} \mathrm{Cl}_{2}$, published previously by DegaSzafran et al. ${ }^{20}$ For more information on this subject the reader can refer the ESI. $\dagger$

The proton chemical shift of $\mathbf{2}$ is about $18.5 \mathrm{ppm}$, indicating a rather strong hydrogen bond, though it does not tell us on which side of the bridge the proton is located. To figure this out we have used additional information. In the solid state the complex 2 shows two structures, both with $\mathrm{BeCOOH} \cdots{ }^{-} \mathrm{OOCCF}_{3}$ geometry, $r(\mathrm{OO})=2.488 / 2.565 \AA^{21} .^{21}$ Besides, the betainium displays lower acidity than the trifluoroacetic acid, $\mathrm{p} K_{\mathrm{a}}$ (betainium $)=1.8,{ }^{32} \mathrm{p} K_{\mathrm{a}}\left(\mathrm{CF}_{3} \mathrm{COOH}\right) \approx 0.5$. These considerations allow us to assume that in $\mathbf{2}$ dissolved in $\mathrm{CDF}_{3} / \mathrm{CDF}_{2} \mathrm{Cl}$ the betaine moiety is protonated, while the negative charge is accumulated on the carboxylic group of the trifluoroacetate, as shown in Fig. 1. Further support for the attribution comes from the temperature dependence, which is discussed below. As it was already mentioned for complex $\mathbf{1}$, the single H-bond geometry associated with the complex in solution is an approximation. In a more realistic picture, the thermal fluctuation of the solvent molecules creates the ensemble of geometries which differ by the momentous structure of the solvation shell. However, for the purposes of this work the assumption of the single H-bond geometry seems to be sufficient and the reported geometry corresponds to the proton position averaged over the solvatomers and over the normal vibrations.

Upon lowering the temperature from $160 \mathrm{~K}$ to $120 \mathrm{~K}$ the dielectric constant of the solvent increases and the bridging proton signal of 2 shifts to the high field by $0.1 \mathrm{ppm}$. This means that the hydrogen bond becomes weaker and $\mathrm{O} \cdots \mathrm{O}$ distance slightly increases. The driving force for this geometric change is most likely the preferential stabilization of the structures with a larger dipole moment in a more polar solvent. ${ }^{1}$ For 2, the more the proton is shifted to the betaine side, the larger is the negative charge on the trifluoroacetate, thus the larger is the overall dipole moment of the complex, because the positive charge compensating the $(\mathrm{OHO})^{-}$ fragment is fixed on one side of the H-bond. This scenario is schematically shown by the two bottom structures in Fig. 4b. The discussion of Fig. $4 \mathrm{~b}$ will be continued for complexes 3-5.

Betaine acid complexes 3, 4 and 5. Like the complex 2, complexes 3-5 are neutral. The proton position can be found if one considers the changes in the ${ }^{1} \mathrm{H}$ chemical shifts in the series 3-4-5, in which the acidity of the proton donor increases $\left(\mathrm{p} K_{\mathrm{a}}\left(\mathrm{CH}_{3} \mathrm{COOH}\right)=4.80, \quad \mathrm{p} K_{\mathrm{a}}\left(\mathrm{CH}_{2} \mathrm{ClCOOH}\right)=2.65\right.$, $\left.\mathrm{p} K_{\mathrm{a}}\left(\mathrm{CCl}_{2} \mathrm{HCOOH}\right)=1.37\right)$. In this order the ${ }^{1} \mathrm{H}$ signal shifts to the low field (see Fig. 3a-c), indicating the proton 
displacement towards the $\mathrm{H}$-bond center, which proves that in complexes $\mathbf{3}, \mathbf{4}$ and $\mathbf{5}$ the bridging proton is located closer to the donor, leaving the carboxylic group of betaine negatively charged.

The similarity in the structures translates into the similarity of the temperature dependencies of the bridging proton chemical shifts. For each complex when the temperature is lowered the signals of the bridging proton shift to the low field. Upon cooling from $160 \mathrm{~K}$ to $120 \mathrm{~K}$ the ${ }^{1} \mathrm{H}$ signal of 3 shifts to the low field by $0.35 \mathrm{ppm}$, for 4 by $0.51 \mathrm{ppm}$ and for 5 by $0.26 \mathrm{ppm}$. The displacement of the signal indicates the shift of the proton to the $\mathrm{H}$-bond center. As it was mentioned previously, the driving force of the proton displacement is the stabilization of the polar structures in the polar solvent. Symmetrisation of the hydrogen bond ( $\mathrm{O} \cdots \mathrm{O}$ shortening) and the increase of the dipole moment are consistent only with the structures of the type $\mathrm{BeCOO}^{-} \cdots \mathrm{HOOCR}$, with the proton located on the acid side, in contrast to complex 2 . This scenario is illustrated by the two upper structures in Fig. 4b. The whole set of structures shown in Fig. 4b corresponds not to a single complex, but rather to a series of complexes, each covering only a fraction of the proton transfer pathway when the temperature or the polarity of the solvent is changed. Fig. $4 \mathrm{~b}$ can also be seen from the other angle: it describes the structural changes in a complex of betaine with a carboxylic acid if the proton donating ability of the latter was continuously changed, while the temperature and the solvent polarity are kept constant.

Betaine hydrofluoric acid 6. The structure of $\mathbf{6}$ as shown in Fig. 1 can be confirmed by the value of the ${ }^{1} J(\mathrm{HF})$ coupling constant, which is $300 \mathrm{~Hz}$, see Fig. $3 \mathrm{~d}$. The ${ }^{1} J(\mathrm{HF})$ coupling constant for free HF molecule is around $600 \mathrm{~Hz},{ }^{33}$ while the coupling for the central-symmetric $(\mathrm{FHF})^{-}$anion is around $124 \mathrm{~Hz}^{34}$ The $\mathrm{BeCOO}^{-}$. . HF structure is further supported by the temperature dependence: upon lowering the temperature the bridging proton signal shifts to the low field, in the same way as it does for complexes $\mathbf{3 , 4}$ and $\mathbf{5}$. At the same time, the ${ }^{1} J(\mathrm{HF})$ coupling decreases from $301 \mathrm{~Hz}$ to $287 \mathrm{~Hz}$, indicating the increase of the $r(\mathrm{HF})$ distance. The direction of the structural changes resembles that found previously for the $\mathrm{CH}_{3} \mathrm{COO}^{\delta-} \ldots \mathrm{H} \ldots{ }^{\delta-} \mathrm{F}$ complex, though in the latter case the hydrogen bond was found to be quasi center-symmetric. ${ }^{35}$

\section{Estimation of the $\mathrm{H}$-bond geometry from $\mathrm{H}$-bond correlations}

H-bond correlations for complexes 1-5. In a recent series of publications we have established the correlation between the ${ }^{1} \mathrm{H}$ NMR chemical shifts and the OHO hydrogen bond geometry. ${ }^{16,31}$ These correlations rely on the interdependence of the two hydrogen bond distances $r_{1}=r(\mathrm{OH})$ and $r_{2}=r(\mathrm{HO})$ or their combinations. ${ }^{36}$

$$
q_{1}=\frac{1}{2}\left(r_{1}-r_{2}\right) \text { and } q_{2}=r_{1}+r_{2} .
$$

For linear hydrogen bonds $q_{1}$ represents the distance of $\mathrm{H}$ from the hydrogen bond center and $q_{2}$ the heavy atom distance. A general dependence of $q_{2}$ on $q_{1}$ which is valid for all $\mathrm{OHO}$ hydrogen bonds is depicted as a solid line in Fig. 5a (adapted from ref. 31). As it was shown by the combination of solid state NMR and crystallographic methods, a fairly good correlation

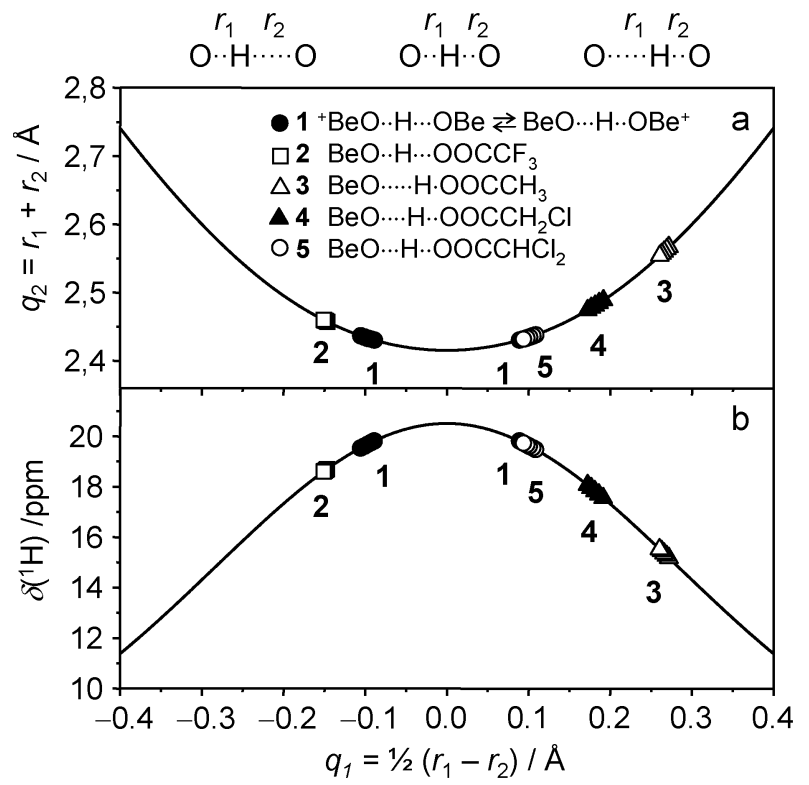

Fig. 5 OHO hydrogen bond correlations adapted from ref. 31. (a) Geometric correlation between $q_{1}$ and $q_{2}$ values. (b) ${ }^{1} \mathrm{H}$ NMR correlation according to eqn (2). Data points correspond to experimentally measured ${ }^{1} \mathrm{H}$ NMR chemical shifts for complexes 1-5 fitted to the solid correlation curves. The resulting $\mathrm{H}$-bond geometries are collected in Table 2 .

exists between the ${ }^{1} \mathrm{H}$ NMR chemical shift and the geometry of an OHO hydrogen bond. ${ }^{16,31,37-41}$ This correlation is illustrated as a solid line in Fig. 5b which was calculated using the following equation:

$$
\delta_{\mathrm{H}}=6+15.3 \exp \left(-6.2 q_{1}^{2}\right) .
$$

Here we use the hydrogen bond correlations to convert the experimentally measured ${ }^{1} \mathrm{H}$ NMR chemical shifts of complexes 1-5 into the interatomic distances $r(\mathrm{OH})$ and $r(\mathrm{HO})$. The points in Fig. 5a and b were obtained as follows. Firstly, the experimental ${ }^{1} \mathrm{H}$ chemicals shifts (Table 1) were converted into $q_{1}$. Secondly, the $q_{2}$ values were found from the $q_{1}$ values using the correlation shown in Fig. 5a. The subset of the resulting distances is collected in Table 2, while the complete set is given in ESI. $\dagger$

H-bond correlations for complex 6. There is only one publication reporting the NMR hydrogen bond correlation for OHF hydrogen bonds. ${ }^{35}$ Though the model used in ref. 35 is more crude than the one used for the OHO bonds, we have used the former to estimate the $r(\mathrm{OH})$ and $r(\mathrm{HF})$ distances which would give the best fitting of the experimentally observed ${ }^{1} \mathrm{H}$ chemical shift and ${ }^{1} J(\mathrm{HF})$ coupling constant, see the bottom line of Table 2. For comparison, we also give the $r(\mathrm{OF})$ distance in an OHF hydrogen bond of a compound similar to 6, $\mathrm{N}$-methylpiperidine betaine hydrofluoride. ${ }^{18}$

Analysis of the temperature dependencies of $\mathbf{H}$-bond geometry for complexes 1-6. It can be seen from Table 2 and Fig. 5 that in all cases the lowering of the temperature from $160 \mathrm{~K}$ to $120 \mathrm{~K}$ changes the $q_{2}$ by less than $0.02 \AA$ and $q_{1}$ by less than $0.03 \AA$. These changes, which might be considered minor, are nevertheless clearly manifested in the NMR spectra, proving it 
Table 2 Hydrogen bond geometries $r(\mathrm{OH})$ and $r(\mathrm{HO})$ estimated from ${ }^{1} \mathrm{H}$ NMR chemical shifts for complexes 1-5 using H-bond correlations (see text for details). The literature X-ray data are given for comparison

\begin{tabular}{|c|c|c|c|c|c|}
\hline & $T / \mathrm{K}$ & $r(\mathrm{OH}) / \AA$ & $r(\mathrm{HO}) / \AA$ & $r(\mathrm{OH})+r(\mathrm{HO}) / \AA$ & $r(\mathrm{OO}) / \AA ̊ \mathrm{~A}(\mathrm{X}$-ray $)$ \\
\hline \multirow[t]{3}{*}{1} & 293 & & & & \multirow[t]{3}{*}{$2.457^{a}$} \\
\hline & 160 & 1.1128 & 1.3239 & 2.4367 & \\
\hline & 120 & 1.1264 & 1.3040 & 2.4304 & \\
\hline \multirow[t]{3}{*}{2} & 293 & & & & \multirow[t]{9}{*}{$2.565 / 2.488^{b}$} \\
\hline & 160 & 1.3753 & 1.0821 & 2.4574 & \\
\hline & 120 & 1.3809 & 1.0791 & 2.4600 & \\
\hline \multirow[t]{2}{*}{3} & 160 & 1.0115 & 1.5551 & 2.5666 & \\
\hline & 120 & 1.0165 & 1.5375 & 2.5540 & \\
\hline \multirow[t]{2}{*}{4} & 160 & 1.0528 & 1.4358 & 2.4886 & \\
\hline & 120 & 1.0647 & 1.4095 & 2.4742 & \\
\hline \multirow[t]{3}{*}{5} & 160 & 1.1103 & 1.3277 & 2.4380 & \\
\hline & 120 & 1.1223 & 1.3098 & 2.4321 & \\
\hline & & $r(\mathrm{OH}) / \AA$ & $r(\mathrm{HF}) / \AA$ & $r(\mathrm{OH})+r(\mathrm{HF}) / \AA$ & $r(\mathrm{OF}) / \AA$ (X-ray) \\
\hline \multirow[t]{3}{*}{6} & 100 & & & & \multirow[t]{3}{*}{$2.3788^{c}$} \\
\hline & 160 & 1.3600 & 1.0367 & 2.3967 & \\
\hline & 120 & 1.3435 & 1.0450 & 2.3885 & \\
\hline \multicolumn{6}{|c|}{$\begin{array}{l}{ }^{a} \text { Ref. } 42 .{ }^{b} \text { Ref. } 21 .^{c} \text { Ref. } 18 \text {, value corresponds to } N \text {-methylpiperidine } \\
\text { betaine hydrofluoride. }\end{array}$} \\
\hline
\end{tabular}

to be a sensitive tool able to detect and quantify small changes in geometry of intermolecular complexes.

The decrease in $q_{2}$ upon lowering the temperature from $160 \mathrm{~K}$ to $120 \mathrm{~K}$ is larger for complexes 3 and $\mathbf{4}(-0.0126 \AA$ and $-0.0144 \AA$, respectively) and smaller for complex $\mathbf{5}$ $(-0.0059 \AA)$. For complex $2 q_{2}$ increases upon lowering the temperature and the magnitude of the change is the smallest in the series: $+0.0026 \AA$. The tentative reason for this is as follows. In the order 3-4-5-2 the bridging proton is gradually transferred to the betaine side and thus the overall dipole moment of the complex increases. The larger is the dipole moment, the better are the solvent molecules ordered around the solute and lowering the temperature induces only small changes in the structure of the solvation shell, which translate into the small geometric changes. One could argue that the closer is the bridging proton to the $\mathrm{H}$-bond center, the higher is the proton polarizability; thus the hydrogen bond geometry should be more responsive to the change in the external conditions. Apparently, in our case this does not happen and the rationalization involving the overall dipole moment of the complex seems to suffice.

\section{Conclusions}

We conclude that in the symmetric homo-conjugated cationic complex 1 the effects of the intermolecularly placed counterion (trifluoroacetate) on the geometry of the $(\mathrm{OHO})^{-}$bridge are minimized, as they have the same charge and are likely to be separated. In contrast, the counterion effects are amplified in neutral complexes 2-6, because the position of the positively charged fragment, which compensates the charge of the $(\mathrm{OHO})^{-}$bridge, is fixed intramolecularly and asymmetrically with respect to the hydrogen bond.

The temperature dependence of the bridging proton position could be explained by considering the ordering of the dipoles of the solvent around the solute at lower temperatures. For complex 1 this ordering stabilizes the structures with the more compact negative charge (shorter $\mathrm{O} \cdots \mathrm{O}$ distance). For complexes 2-6 the solvent ordering preferentially stabilizes the structures with the larger overall dipole moment, which can mean either hydrogen bond lengthening (2) or contraction (3-6), depending on the initial proton position, $\mathrm{Be}^{+} \mathrm{COO}-\mathrm{H} \cdots{ }^{-} \mathrm{OOCR}$ or $\mathrm{Be}^{+} \mathrm{COO}^{-} \ldots \mathrm{H}-\mathrm{OOCR}$, respectively. The temperature effects on the $\mathrm{O} \cdots \mathrm{O}$ distance lie within the range $0.002-0.014 \AA$.

\section{References}

1 (a) J. F. Haw, T. Xu, J. B. Nicholas and P. W. Goguen, Nature, 1997, 389, 832-835; (b) G. Zundel, J. Mol. Struct., 1994, 322, 33-42; (c) P. M. Tolstoy, S. N. Smirnov, I. G. Shenderovich, N. S. Golubev, G. S. Denisov and H.-H. Limbach, J. Mol. Struct., 2004, 700, 19-27; (d) T. Kuc, Z. Pawełka and L. Sobczyk, Phys. Chem. Chem. Phys., 2001, 3, 5201-5207.

2 J. E. Del Bene and M. J. T. Jordan, J. Phys. Chem. A, 2002, 106, 5385-5392.

3 M. Pietrzak, J. P. Wehling, S. Kong, P. M. Tolstoy, I. G. Shenderovich, C. Lopez, R. M. Claramunt, J. Elguero, G. S. Denisov and H.-H. Limbach, Chem.-Eur. J., 2010, 16, 1679-1690.

4 (a) D. B. DuPre, J. Phys. Chem. A, 2003, 107, 10142-10148; (b) C. L. Perrin and J. B. Nielson, J. Am. Chem. Soc., 1997, 119, 12734-12741.

5 R. D. Bach, O. Dmitrenko and M. N. Glukhovtsev, J. Am. Chem. Soc., 2001, 123, 7134-7145.

6 Y. Pan and M. A. McAllister, J. Am. Chem. Soc., 1998, 120, $166-169$.

7 N. S. Golubev, I. G. Shenderovich, P. M. Tolstoy and D. N. Shchepkin, J. Mol. Struct., 2004, 697, 9-15.

8 M. Garcia-Viloca, A. González-Lafont and J. M. Lluch, J. Am. Chem. Soc., 1999, 121, 9198-9207.

9 M. Dracinsky and P. Bour, J. Chem. Theory Comput., 2010, 6, 288-299.

10 T. Murakhtina, J. Heuft, E. J. Meijer and D. Sebastiani, ChemPhysChem, 2006, 7, 2578-2584.

11 A. K. Soper, Chem. Phys., 2000, 258, 121-137.

12 A. Dallmann, M. Pfaffe, C. Mugge, R. Mahrwald, S. A. Kovalenko and N. P. Ernsting, J. Phys. Chem. B, 2009, 113, 15619-15628.

13 S. Ebbinghaus, S. J. Kim, M. Heyden, X. Yu, M. Gruebele, D. M. Leitner and M. Havenith, J. Am. Chem. Soc., 2008, 130 , 2374-2375.

14 N. Huse, S. Ashihara, E. T. J. Nibbering and T. Elsaesser, Chem. Phys. Lett., 2005, 404, 389-393.

15 V. I. Chizhik, I. S. Podkorytov, A. P. Kaikkonen and V. I. Mikhailov, J. Magn. Reson., Ser. A, 1996, 123, 1-6.

16 P. M. Tolstoy, P. Schah-Mohammedi, S. N. Smirnov, N. S. Golubev, G. S. Denisov and H.-H. Limbach, J. Am. Chem. Soc., 2004, 126, 5621-5634.

17 C. L. Perrin and J. S. Lau, J. Am. Chem. Soc., 2006, 128, $11820-11824$.

18 M. Szafran, Z. Dega-Szafran, R. Thaimattam and M. Jaskolski, J. Mol. Struct., 2004, 706, 49-55.

19 D. Dogzisz, M. M. Ilczyszyn and M. Ilczyszyn, J. Mol. Struct., 2002, 606, 123-137.

20 Z. Dega-Szafran, A. Komasa, M. Grundwald-Wyspiafiska, M. Szafran, G. Buczak and A. Katrusiak, J. Mol. Struct., 1997, 404, 13-23.

21 V. H. Rodrigues, J. A. Paixāo, M. M. R. R. Costa and A. Matos Beja, Acta Crystallogr., Sect. C: Cryst. Struct. Commun., 2001, 57, 761-763.

22 Z. Dega-Szafran, M. Szafran, H. Szymusiak, R. Zieliński and M. Przedwojska, J. Mol. Struct., 2005, 744, 457-463.

23 J. Baran, A. J. Barnes, B. Engelen, M. Panthöfer, A. Pietraszko, H. Ratajczak and S. Sledz, J. Mol. Struct., 2000, 550, 21-41.

24 Z. Dega-Szafran, M. Jaskólski and M. Szafran, J. Mol. Struct., 2000, 555, 191-201.

25 Z. Dega-Szafran and E. Sokolowska, J. Mol. Struct., 2001, 565, $17-23$.

26 Z. Dega-Szafran, M. Gdaniec, M. Grundwald-Wyspiańska, I. Kowalczyk and M. Szafran, J. Mol. Struct., 1994, 322, 297-308. 
27 Z. Dega-Szafran, A. Antkowiak, M. Grundwald-Wyspiańska, E. Nowak and Z. Kosturkiewicz, J. Mol. Struct., 2002, 605, 309-317.

28 A. Schmidt, A. S. Lindner, J. Casado, J. T. López Navarrete and F. J. Ramírez, Chem. Phys., 2010, 371, 1-3.

29 J. S. Siegel and F. A. I. Anet, J. Org. Chem., 1988, 53, 2629-2630.

30 I. G. Shenderovich, A. P. Burtsev, G. S. Denisov, N. S. Golubev and H.-H. Limbach, Magn. Reson. Chem., 2001, 39, S91-S99.

31 H.-H. Limbach, P. M. Tolstoy, N. Pérez-Hernández, J. Guo, I. G. Shenderovich and G. S. Denisov, Isr. J. Chem., 2009, 49, 199-216.

32 J. C. Ahluwalia, F. J. Millero, R. N. Goldberg and L. G. Hepler, J. Phys. Chem., 1966, 70, 319-323.

33 I. G. Shenderovich, P. M. Tolstoy, N. S. Golubev, S. N. Smirnov, G. S. Denisov and H.-H. Limbach, J. Am. Chem. Soc., 2003, 125, $11710-11720$.

34 I. G. Shenderovich, H.-H. Limbach, S. N. Smirnov, P. M. Tolstoy, G. S. Denisov and N. S. Golubev, Phys. Chem. Chem. Phys., 2002, 4, 5488-5497.
35 N. S. Golubev, P. M. Tolstoy, S. N. Smirnov, G. S. Denisov and H. H. Limbach, J. Mol. Struct., 2004, 700, 3-12.

36 T. Steiner and W. Saenger, Acta Crystallogr., Sect. B: Struct. Sci., 1994, 50, 348-357.

37 R. K. Harris, P. Jackson, L. H. Merwin, B. J. Say and G. Hägele, J. Chem. Soc., Faraday Trans. 1, 1988, 84, 3649-3672.

38 (a) U. Sternberg and E. L. Brunner, J. Magn. Reson., Ser. A, 1994, 108, 142-150; (b) E. L. Brunner and U. Sternberg, Prog. Nucl. Magn. Reson. Spectrosc., 1998, 32, 21-57.

39 T. K. Mildvan and A. S. Harris, Proteins: Struct., Funct., Genet., 1999, 35, 275-282.

40 A. McDermott and C. F. Ridenour, Proton chemical shift measurements in biological solids, Encyclopedia of NMR, Wiley, Sussex, UK, 1996, pp. 3820-3825.

41 T. Emmler, S. Gieschler, H. H. Limbach and G. Buntkowsky, J. Mol. Struct., 2004, 700, 29-38.

42 V. H. Rodrigues, J. A. Paixo, M. M. R. R. Costa and A. Matos Beja, Acta Crystallogr., Sect. C: Cryst. Struct. Commun., 2001, 57, 213-215. 